Please do not remove this page
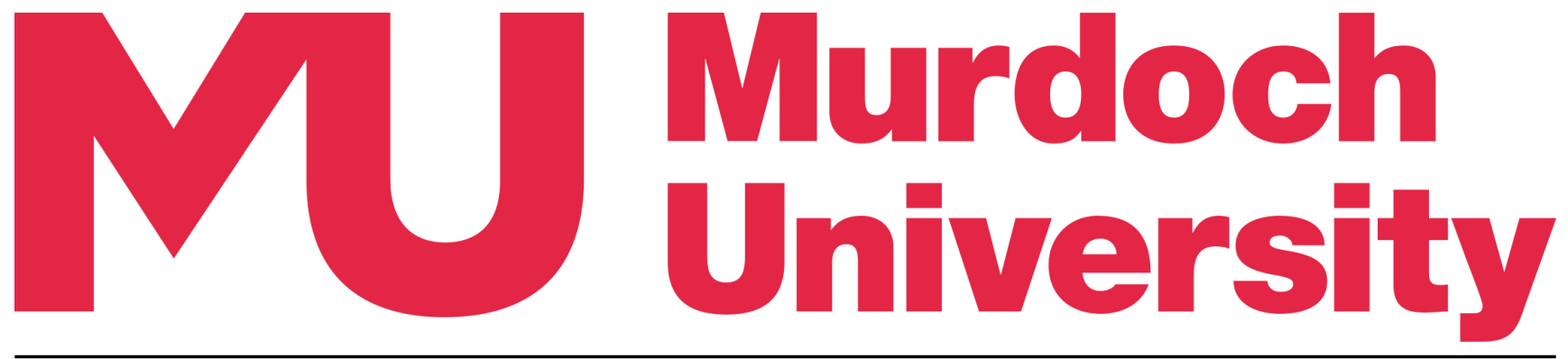

\title{
The viscoelastic behaviour of raw and anaerobic digested sludge: Strong similarities with soft-glassy materials
}

Baudez, Jean; Gupta, Rahul; Eshtiaghi, Nicky; Slatter, Paul

https://researchrepository.rmit.edu.au/esploro/outputs/9921858653901341/filesAndLinks?institution=61RMIT_INST\&index=null

Baudez, J., Gupta, R., Eshtiaghi, N., \& Slatter, P. (2013). The viscoelastic behaviour of raw and anaerobic digested sludge: Strong similarities with soft-glassy materials. Water Research, 47(1), 173-180.

https://doi.org/10.1016/j.watres.2012.09.048

Published Version: https://doi.org/10.1016/j.watres.2012.09.048

Repository homepage: https://researchrepository.rmit.edu.au

(c) 2012 Elsevier Ltd. All rights reserved.

Downloaded On 2023/04/26 17:44:16 +1000 
Thank you for downloading this document from the RMIT Research Repository.

The RMIT Research Repository is an open access database showcasing the research outputs of RMIT University researchers.

RMIT Research Repository: http://researchbank.rmit.edu.au/

\section{Citation:}

Baudez, J, Gupta, R, Eshtiaghi, N and Slatter, P 2013, 'The viscoelastic behaviour of raw and anaerobic digested sludge: Strong similarities with soft-glassy materials', Water Research, vol. 47, no. 1, pp. 173-180.

See this record in the RMIT Research Repository at: http://researchbank.rmit.edu.au/view/rmit:18111

Version: Accepted Manuscript

Copyright Statement: (c) 2012 Elsevier

Link to Published Version:

http://dx.doi.org/10.1016/j.watres.2012.09.048 


\section{The viscoelastic behaviour of raw and anaerobic digested sludge: strong similarities with soft-glassy materials}

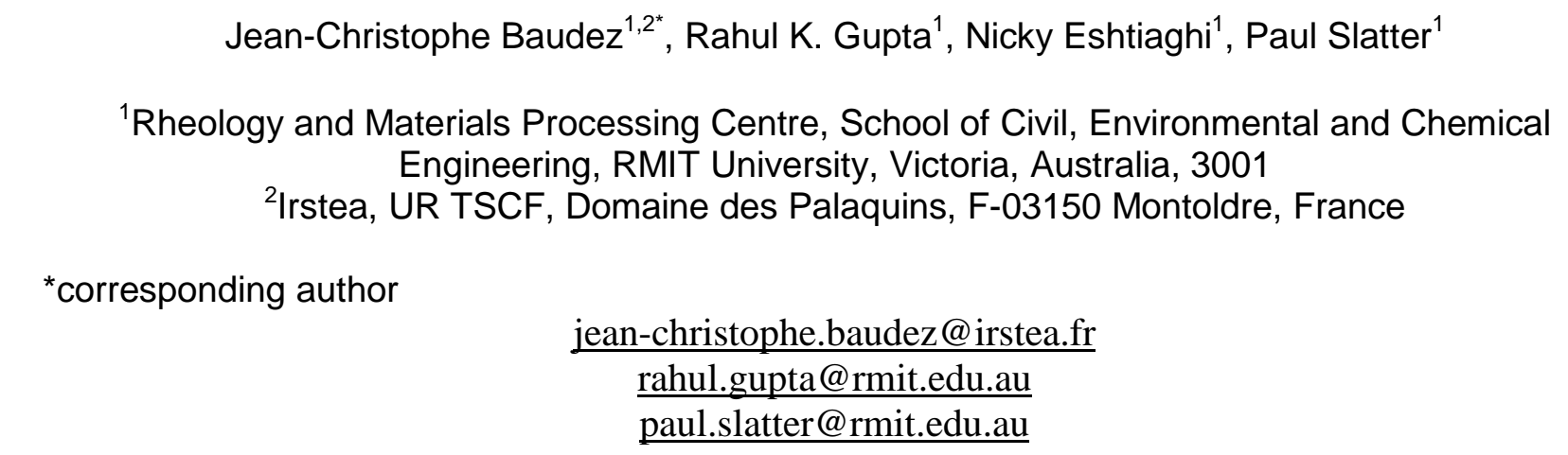
confronted with a dramatically increasing flow of sewage sludge. To improve treatment efficiency, process and material parameters are needed but engineers are dealing with vast quantities of fundamentally poorly understood and unpredictable material Thus, accurate prediction of critically important, but analytically elusive process parameters is unattainable and is a matter of grave concern. Because engineers need reliable flow properties to simulate the process, this work is an attempt to approach sludge rheological behaviour with well-known materials which have similar characteristics. Sludge liquid-like behaviour is already well documented so, we have focused mainly on the solid-like behaviour of both raw and digested sludge by performing oscillatory measurements in the linear and non-linear regimes. We have shown that the viscoelastic behaviour of sludge presents strong similarities with soft-glassy materials but differences can be observed between raw and digested sludge. Finally, we confirm that colloidal glasses and emulsions may be used to model the rheological behaviour of raw and anaerobic digested sludge.

\section{Keywords}

Glassy materials, rheology, sewage sludge, soft matter, time-temperature superposition, viscoelasticity 
Introduction

Sewage sludge production is the residue of wastewater treatment and by definition can't be avoided. In the EU it is produced at more than 30000 tonnes (dry matter) per day and will increase by at least $10 \%$ in 2020 (EUREAU, 2012). These volumes have to be treated and reused.

Slatter (1997, 2001, 2003, 2004 and 2008) has consistently shown that sludge rheology plays a fundamentally important role in analysing the hydrodynamic behaviour of the sludge, as it flows in pipes or in tanks and reactors, such as anaerobic digesters. However, sludge properties continuously evolve due to the ongoing biochemical reactions, and for this reason it cannot be used as a reference material for the design of industrial processes: engineers need reliable and repeatable flow properties to simulate the process. Thus, various researchers attempted to use model fluids instead of sludge, such as kaolin suspension for the yield stress determination (Spinosa and Lotito, 2003), polymeric gels (Legrand et al., 1997), polyvinyl chloride (PVC) suspensions (Bongiovanni, 1998), polystyrene latex (Sanin and Vesilind, 1996), but none of these was particularly successful because each of these model fluids was only representative of a particular application. To model the flow properties of sludge, mainly in its liquid regime, kaolin suspensions are often used (Heritier et al., 2010) because it shows shear-thinning behaviour with a yield stress, modelled with a Herschel-Bulkley model (Masalova et al., 2006). Even if this model fluid can be used to simulate high velocity flows, it is not suitable for simulating the liquid-like behaviour at intermediate shear rates, nor the solid-like behaviour at low shear rates, which appears to be crucial in order to avoid - or at least minimize - dead zones in reactors, such as anaerobic digesters or aeration basins.

Because of its fundamental nature, sludge is a very complex mixture of unknown composition and its rheological behaviour is highly dependent of the treatment processes: accurate prediction of critically important, but analytically elusive, process parameters is unattainable and is a matter of grave concern.

For sake of simplicity, in the following we will only distinguish between raw, activated and anaerobically digested sludge, respectively representative of the outlet of sludge treatment when no tertiary treatment is applied and when anaerobic digestion is implemented. Both are temperature-dependent (Dieude-Fauvel et al., 2009; Baudez and Slatter, 2012), present viscoelastic properties at low shear stress and a shear-thinning behaviour at high shear stress 
(Baudez and Coussot, 2001, Baudez et al., 2011), but at intermediate shear stresses, raw sludge is a thixotropic material (Tabuteau et al., 2006, Baudez, 2008) with ageing effects (Baudez, 2008) while anaerobic digested sludge highlights shear banding (Baudez et al., 2011).

71 Raw and digested sludge are mainly composed of water (more than 95\%) and the remaining part is made of organic matter and bacteria which tend to aggregate forming flocs. That is the usual 'chemical' definition of sludge: organic flocs suspended in water. However, physically, sludge can also be visualised as interacting particles in a suspending medium: bacteria form extra polymeric substances (EPS), finally presenting a three-dimensional gel-like biofilm matrix (Wingender et al., 1999). EPS are highly charged polymers that interact with water in a manner similar to gels (Keiding et al., 2001, Sutherland, 2001). They interact with divalent metal ions to form sludge flocs in both aerobic and anaerobic treatment systems (Higgins and Novak, 1997). Flocs in activated sludge usually carry negative charge at neutral $\mathrm{pH}$. It has been found that the extracellular polymeric substances (EPS) contribute to the negative surface charge of the sludge flocs (Jia et al., 1996; Liao et al., 2001). As regards the influence of the anaerobic digestion, Jia et al. (1996) also observed that during batch tests both surface charge and EPS content change significantly. Polysaccharides and proteins were found to be the most significant surface polymers in activated (raw) sludge (Forster, 1983), and the two types of binding mechanisms between water molecules and the EPS structure are considered to be electrostatic and hydrogen bonds (Flemming, 1996).

Digestion leads to the transfer of bigger flocs into smaller ones (Mahmoud et al., 2006) and disintegration of the organics brings the solids to a homogeneous grain structure, with an increase of the quantity of colloidal particles (Turovskii and Matai, 2006) and a decrease of EPS (Karapangiotis et al., 1998). The anaerobic digestion data showed strong correlations between soluble protein generation and ammonium production (Park et al., 2006). The most important constituents in digested sludge are proteins and lipopolysaccharides (Forster, 1983), which are amphiphile lipids with both hydrophilic and hydrophobic heads. Novak et al. (2003) found the protein concentration was 3-5 times greater than the polysaccharide concentration in anaerobic systems compared to aerobic ones. They also noticed an increase of monovalent cations.

From a physical point of view, anaerobic digested sludge appears to be a stable suspension with low settling ability (Namer and Ganczarczyk, 1993) and low surface charge (Forster, 2002) indicating that interactions are more steric than electrostatic. 
Moreover, Mikkelsen and Keiding (2002) showed that the ratio between protein and polysaccharides are more or less of the same order between activated and (mesophilic) digested sludge, but the degree of dispersion is 20 times higher after anaerobic digestion, indicating that sludge structure is strongly affected by anaerobic digestion.

In this paper, we intend to draw parallels between well-known materials and sludge. These wellknown materials could then be used a model fluids to emulate the rheological behaviour of sludge for the investigation and design of treatment technologies. Because the liquid-like behaviour of sludge is well documented, we will intentionally focus on the solid-like behaviour of both raw and digested sludge by performing oscillatory measurements in the linear and non-linear viscoelastic regimes. We show that the viscoelastic behaviour of sludge presents strong similarities with softglassy materials but differences can be observed between raw and digested sludge. Stress and frequency sweeps were conducted at different temperatures to demonstrate that Brownian motion also plays a role in the build-up and break-down of sludge structure. Finally, we demonstrate that colloidal glasses and emulsions may be used to model the rheological behaviour of raw and anaerobic digested sludge.

Materials and methodology

Sludge was obtained from the Mount Martha wastewater treatment plant (Melbourne, Victoria, Australia) at the inlet (called raw sludge in the following) and the outlet (called digested sludge) of the digester number 1 . The initial concentration of the raw sludge was found to be $45 \mathrm{~g} \cdot \mathrm{L}^{-1}$ (this relatively high concentration was obtained after flotation thickening, without chemical conditioning) while the solid concentration of the digested sludge was found to be $18.5 \mathrm{~g} \cdot \mathrm{L}^{-1}$. The latter was also gently concentrated to $32 \mathrm{~g} \cdot \mathrm{L}^{-1}$ (and $42 \mathrm{~g} \cdot \mathrm{L}^{-1}$ after a second sampling for time sweep experiments) by using a Buchner vacuum. These concentrations were chosen to be representative of thickened sludge which is more often used in digesters. Digested samples were stored at $4^{\circ} \mathrm{C}$ for 30 days before experiments were conducted to ensure no temporal variability, allowing us to use the same material for several days of testing. This technique was successfully used by Curvers et al. (2009). 
On the other hand, because of their high degree of fermentation, raw sludge was stored only 5 days before experiments. Although storage implied changes in the composition of the raw sludge, considering the duration of rheological characterisation, especially the frequency sweep, we needed to consider raw sludge as a 'stable' material, from both the biological and chemical points of view during our whole investigation. Because changes are very fast the 72 first hours (Baudez and Coussot, 2001), 5 days appears to be the shortest duration that we could manage with in order to ensure that we dealt with the same material in a short window of 24 hours.

Time, stress and frequency sweep measurements were carried out with a stress-controlled DSR200 instrument from Rheometric Scientific, connected to a temperature controlled water bath.

The rheometer was equipped with a cup and bob geometry (inner diameter: $29 \mathrm{~mm}$, outer diameter: $32 \mathrm{~mm}$, length: $44 \mathrm{~mm}$ ). Temperature varied from 10 to $80^{\circ} \mathrm{C}$ (high temperatures were applied to highlight thermal phenomena).

To avoid evaporation, sludge was covered with a thin film of known viscosity Newtonian oil: oil and sludge are not miscible, as evidenced by oil removal processes in wastewater treatment plants.

Before each measurement, sludge was strongly pre-sheared at a shear rate of $500 \mathrm{~s}^{-1}$ for 5 minutes and then left at rest respectively for 2 minutes for time sweeps, 5 minutes for strain sweeps and 1 hour for frequency sweeps. This procedure allowed us to obtain reproducible results (Baudez et al., 2011).

Results and discussion

Time sweep

150 Under constant stress, low enough to be in the linear viscoelastic regime (Ayol et al., 2006) and 151 constant frequency, raw sludge aged with a monotonic decrease of the shear strain while the digested sludge reached an equilibrium state after less than 15 minutes (Figure 1 ). Shear history can be considered as negligible for digested sludge, but not for raw sludge which undergoes an ageing process.

Note that, due to continuous bacterial activity, this ageing process must be considered as a shortterm characteristic: fermentation induces a fluidisation of the material (Baudez and Coussot, 2001) 
and over long experimental times, under constant stress and constant frequency, the shear strain will increase.

\section{Strain sweep}

For both raw and digested sludge, G' is nearly constant at low shear strain, suggesting a linear viscoelastic regime (LVE), in agreement with the results of Ayol et al. (2006). Then, both moduli become strain dependent with G' decreasing and G" passing through a peak before decreasing as well (Figure 2). Of further interest is the strain-dependence of G' and G": when G">G', they both follow a power-law model (Figure 3), such as:

$$
\begin{aligned}
& G^{\prime \prime} \propto \gamma^{-n} \\
& G^{\prime} \propto \gamma^{-2 n}
\end{aligned}
$$

This peculiar behaviour is known to be the hallmark of soft-glassy materials (Wyss et al., 2005) and has been noticed for many other systems such as colloidal glasses (Mason and Weitz, 1995), emulsions (Mason et al., 1997) and gels (Altmann et al., 2004).

However, while the transition from a solid-like to a liquid-like behaviour is smooth with digested sludge, raw sludge suddenly yields: G' is divided by almost 10 and the strain drops sharply from 5 to $16 \%$ when the applied stress changes from 0.43 to $0.46 \mathrm{~Pa}$ (Figure 2 and insert).

It is also worth noting that the peak in G" vanishes when the temperature increases (figure 4) and then disappears at very high temperatures for digested sludge while it appears to remain at almost constant amplitude with the raw sludge (figure 5).

At this point, one can conclude that both raw and digested sludge present similarities with softglassy materials, but also some differences:

- digested sludge appears not to be an "out-of-equilibrium" material (at least at the considered concentration) and tends to behave like a simple colloidal suspension;

- raw sludge is an out-of-equilibrium material which abruptly yields from a solid-like to a liquid-like behaviour.

These differences may be attributed to the degree of dispersion of digested sludge which is 4 times higher than activated sludge, and the EPS concentration which is 2 times lower for digested sludge: according to Mikkelsen and Keiding (2006), the EPS fraction is the most important 
parameter with respect to floc structure and the presence of large EPS quantities may increase the interaction via entanglement, which induce relaxation processes (Thurston, 2001).

In both cases, increase of temperature induces a decrease of rheological characteristics: raw and digested sludge become more and more fluid (Figures 4 and 5) and we emphasise a proportionality between water viscosity and the strain at the cross-point where G'=G" (Figure 6) and above. Because water viscosity follows an Arrhenius law with temperature, we can deduce from Figure 6 that when $G^{\prime \prime}>G^{\prime}$, the viscoelastic characteristics follow an Arrhenius law too, with the same activation energy as water viscosity.

These results suggest that the same molecular movements are involved in the temperaturedependence of loss modulus and storage modulus in the liquid-like regime and water viscosity.

However, in the solid-like regime, (G'>G"), both G' and G" follow a non-Arrhenius Vogel-

Tammann-Fulcher (VTF) equation with the temperature (Figure 7) with almost the same $T_{0}$ (Table 1):

$G^{\prime}=A \cdot \exp \left(\frac{E a}{R \cdot\left(T-T_{0}\right)}\right)$

This relation contains three adjustable parameters, $A$, Ea and $T_{0}$, with $T_{0}$ being the temperature where 'free volume' disappears in many 'free volume' models. The observed deviation from the Arrhenius law in the solid-like regime $\left(G^{\prime}>G^{\prime \prime}\right)$ is similar to what it is observed with fragile glasses (Kobayashi and Takahashi, 2008): when $G^{\prime}>G^{\prime \prime}$, raw and anaerobic digested sludge can be seen as an amorphous solid; but they behave more like disordered liquids when G">G'.

Table 1: Parameters of Equation (2) for the raw and digested sludge (at 3.2\%) submitted to a constant shear stress respectively equivalent to $a 1$ and $2 \%$ shear strain.

\begin{tabular}{|c|c|c|}
\hline & $\mathrm{G}^{\prime}$ & $\mathrm{G}^{\prime}$ \\
\hline \multicolumn{3}{|c|}{ Digested sludge } \\
\hline $\mathrm{A}[\mathrm{Pa}]$ & 9.58 & 1.58 \\
\hline $\mathrm{Ea} / \mathrm{R}\left[{ }^{\circ} \mathrm{C}\right]$ & 35.00 & 13.77 \\
\hline $\mathrm{T}_{0}\left[{ }^{\circ} \mathrm{C}\right]$ & 98.36 & 97.91 \\
\hline \multicolumn{3}{|c|}{ Raw sludge } \\
\hline $\mathrm{A}[\mathrm{Pa}]$ & 12.75 & 1.872 \\
\hline
\end{tabular}




\begin{tabular}{|c|c|c|}
\hline $\mathrm{Ea} / \mathrm{R}\left[{ }^{\circ} \mathrm{C}\right]$ & 17.10 & 15.99 \\
\hline $\mathrm{T}_{0}\left[{ }^{\circ} \mathrm{C}\right]$ & 95.02 & 94.88 \\
\hline
\end{tabular}

Frequency sweep

In the linear regime (shear strain lower than 2\%), both raw and digested sludge show a weak power-law dependence (power law index smaller than 0.1) with the frequency (figure 8) with G' and G" in a nearly constant ratio (\#0.15). In the highest frequency range the digested sludge presents a shallow minimum in the G" curve.

In the non-linear regime (shear strain higher than 10\%), digested sludge exhibits a plateau for G' at intermediate frequencies and a localized minimum for G" (Figure 9) while raw sludge exhibits a plateau for both G' and G" (data not shown). At lower frequencies, for both sludges, the loss modulus varies linearly with the frequency while the storage modulus follows a power-law with a power-law index higher than 1 which also increases with the temperature, at least for the digested sludge (figure 9-10):

$G^{\prime} \propto \omega^{n}(n>1), G^{\prime \prime} \propto \omega$

Moreover, the linearity between frequency and loss modulus at low frequencies suggests similarities of the behaviour at all temperatures investigated in this work. Unfortunately, as previously mentioned such an assumption cannot be verified with raw sludge which is a highly fermentable and continuously changing material: frequency sweep experiments are time consuming and as the temperature increases, fermentation kinetics also increase. Consequently in such a case it is simply not possible to assume constant material properties throughout the experiment. However, with digested sludge, we can make this assumption and by horizontally shifting the frequency-dependence curves we obtain a master curve (Figure 11) for digested sludge samples at two different concentrations

Surprisingly, the horizontal shift factor presents a linear relationship with the water viscosity for the lower concentration (Figure 12) but not for the higher concentration, indicating that thermal agitation cannot be considered as a key factor when the concentration increases. Consequently, other interactions can no longer be neglected, such as hydrophobic or electrostatic forces (Mikkelsen and Keiding, 2002). 
237 Table 2 summarizes the main characteristics of the raw and digested sludge, including results get 238 from the literature. First of all, anaerobic digestion not only modifies sludge composition but also its 239 rheological behaviour. Consequently, these changes have to be taken into account in the flow 240 behaviour analysis of material being digested in order to improve mixing and homogenisation.

241 If we try to establish a parallel with well-known materials, these features (of raw and digested 242 sludge) are similar to those found in the literature regarding the viscoelastic behaviour of soft243 glassy materials (Chen et al., 2010). However, soft-glassy materials encompass many materials 244 such as pastes, foams, emulsions, colloids, etc. with their own specific characteristics. Looking at 245 the ageing process; emulsions (Mason and Weitz, 1995) or paints (Baldewa and Joshi, 2011) 246 could be seen as a convenient model for digested sludge. This assumption can be strengthened 247 with the fact that, according to the literature (Forster, 1983), digested sludge is composed mainly of protein and lipopolysaccharides which can be seen as amphiphile materials. Besides, raw sludge highlights a more complex behaviour, with ageing and abrupt yielding, but also with temperature dependence, which is reminiscent of (thixotropic) colloidal gels (Joshi et al., 2008). This last assumption is in agreement with the work of Legrand et al. (1998) and Dursun and Dentel (2009) who considered that the gel approach is a pertinent conceptual model for sludge structure.

253 Even if these assumptions still have to be clearly established, it may signify that during anaerobic digestion sludge evolves from a colloidal gel-like material to an emulsion-like material, and we may have to deal with a mix of emulsion-like and gel-like materials within reactors. Such a complexity may induce a very complex rheological behaviour in terms of mixing and homogenisation 257 (industrial digesters are bigger than $10.000 \mathrm{~m}^{3}$ ).

258 Thus, further work has to be done by comparing all the rheological characteristics of digested and raw sludge with emulsion or paint and with colloidal gels over a broader range of concentrations; 260 but also by looking at the rheological behaviour of sludge during anaerobic digestion, when all the 261 highlighted characteristics coexist. 
Table 2: main characteristics of both raw and digested sludge. The symbol * indicates results coming

\begin{tabular}{|c|c|c|}
\hline 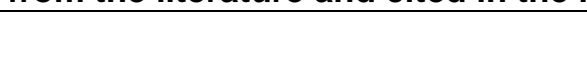 & Raw sludge & Digested sludge \\
\hline Major interactions* & Electrostatic & Steric \\
\hline Power-law rheology* & Yes & Yes \\
\hline Shear thinning behaviour* & Yes & Yes \\
\hline Shear-banding* & No & Yes \\
\hline Ageing after shear rejuvenation & Yes & No \\
\hline $\begin{array}{l}\text { Temperature dependence } \\
\text { (at least in the considered range } \\
\text { of solids concentration) }\end{array}$ & $\begin{array}{c}\text { Non-Arrhenius law (G'>G') } \\
\text { Arrhenius law (G'<G') }\end{array}$ & $\begin{array}{c}\text { Non-Arrhenius law (G'>G') } \\
\text { Arrhenius law (G'<G') }\end{array}$ \\
\hline Time-temperature superposition & Unknown & Yes \\
\hline $\begin{array}{l}\text { Stain dependence of G' and G" } \\
\text { (non-linear regime) }\end{array}$ & $\begin{array}{c}\text { Power-law, } \\
\text { G" passes through a } \\
\text { maximum before abrupt } \\
\text { yielding }\end{array}$ & $\begin{array}{c}\text { Power-law, } \\
\text { G" passes through a } \\
\text { maximum before smooth } \\
\text { yielding }\end{array}$ \\
\hline $\begin{array}{l}\text { Frequency dependence of G' and } \\
\qquad G^{\prime \prime}\end{array}$ & $\begin{array}{c}\text { G'/G" nearly constant (linear } \\
\text { regime) } \\
G^{\prime} \propto \omega^{n}, G^{\prime \prime} \propto \omega \text { (non-linear } \\
\text { regime) }\end{array}$ & $\begin{array}{c}\text { G'}^{\prime} \mathrm{G}^{\prime \prime} \text { nearly constant, } \\
\text { shallow minimum for G" } \\
\text { (linear regime) } \\
G^{\prime} \propto \omega^{n}, G^{\prime \prime} \propto \omega \text { (non-linear } \\
\text { regime) }\end{array}$ \\
\hline
\end{tabular}

Conclusion

The viscoelastic behaviour of raw and anaerobically digested sludge was analysed using oscillatory measurements. We found that both materials present strong similarities with soft-glassy materials: the storage modulus decreases monotonically with the shear strain, while the loss modulus passes through a maximum before decreasing. In the liquid-like regime, when $G^{\prime}<G^{\prime \prime}$, both moduli followed a power-law dependency against frequency. Increase of temperature also 
induced a fluidisation of sludge, with a decrease of rheological characteristics according to both Arrhenius and VTF laws. However, raw and digested sludge have different structure and dominant interactions: also - the ageing process only occurs with raw sludge, not with digested sludge.

In the range of concentrations tested, both sludges are temperature dependent and this behaviour appears to be highly dependent of thermal agitation, with some linear relationship between rheological characteristics and temperature-water viscosity variations.

We have shown that colloidal gels and emulsion can model the rheological behaviour of respectively raw and digested sludge. Thus, this paper opens a new insight into sludge management by empowering engineers to model digested sludge with emulsions and raw sludge with colloidal gels. However, more work has to be done, by comparing all the rheological characteristics of digested and raw sludge with emulsion or paint and with colloidal gels over a broader range of concentrations.

\section{ACKNOWLEDGMENT}

The authors gratefully acknowledge Irstea, Melbourne Water and South East Water (Ltd.) as well as the Research and Innovation Office of RMIT University for providing support for Dr JeanChristophe Baudez's visit to pursue this research.

\section{REFERENCES}

Altmann, N., Cooper-White, J. J., Dunstan, D. E., Stokes, J. R. 2004. Strong through to weak 'sheared' gels. J. Non-Newtonian Fluid Mech. 124, 129-136

Ayol, A., Dentel, S.K., Filibelli, A., 2006. Toward efficient sludge processing using novel rheological parameters: dynamic rheological testing.

Baldewa, B., Joshi, Y.M., 2011. Thixotropy and physical aging in acrylic emulsion paint. Polymer Engineering and Science, DOI 10.1002/pen

Battistoni, P., Fava, G., Cecchi, F., Pava, P., 1991. Rheology of sludge from semi-dry anaerobic digestion of municipal solid waste. Environ. Technol. 12:1-9

Baudez, J.C, Coussot, P., 2001. Rheology of aging, concentrated, polymeric suspensions Application to pasty sewage sludges. J. Rheol. 45(5):1123-1139.

Baudez, J.C., 2008. Physical aging and thixotropy in sludge rheology. Applied Rheology, 18, 13495 1-8.

Baudez, J.C., Markis, F., Eshtiaghi, N., Slatter, P., 2011a. The rheological behaviour of digested sludge. Water Research, 45, 17, 5675-5680..

Baudez, J.C., Slatter, P., 2012. The impact of temperature on the rheological behaviour of anaerobic digested sludge. Submitted to Chemical Engineering.

Bhattacharya S.N., 1981. Flow characteristics of primary and digested sewage sludge. Rheol. Acta 20:288- 298.

Bongiovanni, J.-M., 1998. Traitement des boues résiduaires par l'association en série d'une déshydratation mécanique et d'un séchage thermique, Thèse de doctorat, Université de Pau et des Pays de l'Adour. 
Curvers, D., Saveyn, H., Scales, P.J., Van der Meeren, P., 2009. A centrifugation method for the assessment of low pressure compressibility of particulate suspensions. Chemical Engineering Journal Volume 148, Issue 2-3, 15 May 2009, Pages 405-413

Dieudé-Fauvel, E., VanDamme, H., Baudez, J.C., 2009. Improving rheological sludge characterization with electrical measurements. Chemical Engineering Research and Design. 87, 982-986

Dursun, D; Dentel, S.K., 2009. Toward the conceptual and quantitative understanding of biosolids conditioning: the gel approach. Water Science and Technology, 59, 9, 1679-1685.

EUREAU, 2012. EUREAU POSITION PAPER on how the revision of the Fertiliser Regulation should promote sustainable use of sludge in agriculture (http://eureau.org/sites/eureau.org/files/documents/2012.03.29 EUREAU PP Sust\%20use Sludg e in agri.pdf)

Flemming, H.C., 1996. The forces that keep biofilms together, in Biodeterioration and biodegradation (eds: Sand, W.). DECHEMA Monographs, 133, VCH, Weimheim.

Forster, C.F., 1983. Bound water in sewage sludge and its relationship to sludge surfaces and sludge viscosities. J. Chem. Tech. Biol., 33B:76-84.

Forster, C.F., 2002. The rheological and physico-chemical characteristics of sewage sludge". Enzyme and Microb. Tech., 30(3):340-345.

Héritier, P., Roux, J.C., Dieudé-Fauvel, E., 2010. Impact of sludge mechanical behaviour on spatial distribution parameters obtained with centrifugal spreader. AgEng 2010, International Conference on Agricultural Engineering, Clermont-Ferrand, France

Higgins, M., Novak, T.J., 1997. Characterisation of extracellular protein and its role in bioflocculation. J. Environ. Eng., 123, 479-485.

Jia, X.S., Furumai, H., Fang, H., 1996. Extracellular polymers of hydrogen-utilizing methanogenic and sulfate reducing sludges. Water Science and Technology, 30, 1439-1444.

Joshi, Y.M. ,Reddy, G.R.K.,Kulkarni, A.L., Kumar, N.,Chhabra, 2008. Rheological behaviour of aqueous suspensions of laponite: New insights into the ageing phenomena. Proceedings of the Royal Society A: Mathematical, Physical and Engineering Sciences, Volume 464, Issue 2090, Pages 469-489

Karapangiotis, N.K., Rudd, T., Sterritt, R.M., Lester, J.N., 1998. Extraction and characterisation of extracellular polymers in digested sewage sludge. J. Chem. Technol. Biotechnol., 44, 107-120.

Keiding, K., Wybrandt, L., Nielsen, P.H., 2001. Remember the water : comment on EPS colligative properties. Water Science and Technology, 43, 17-23.

Legrand V., Hourdet, D., Audebert R., Snidaro, D., 1998. Deswelling and flocculation of gel networks: Application to sludge dewatering. Water Research, vol. 32, no12, pp. 3662-3672

Liao, B.Q., Allen, D.G., Droppo, I.G., Leppard, G.G., Liss, S.N., 2001.Surface properties of sludge and their role in bioflocculation and settleability. Wat. Res., 35, 339-350.

Lotito V, Spinosa L, Mininni G, Antonacci R: The rheology of sewage sludge at different steps of treatment. Wat. Sci. Tech., 36, 11 (1997), 79-85.

Mahmoud, N., Zeeman, G., Gijzen, H., Lettinga, G., 2006. Interaction between digestion conditions and sludge physical characteristics and behaviour for anaerobically digested primary sludge. Biochemical Engineering Journal, Volume 28, Issue 2, Pages 196-200.

Masalova, I., Malkin, A.Y., Kharatiyan, E., Haldenwang, R., 2006. Scaling in pipeline flow of kaolin suspensions. Journal of Non-Newtonian Fluid Mechanics 136 (1), pp. 76-78

Mason, T. G., Lacasse, M.D., Grest, G.S., Levine, D., Bibette, J., Weitz, D.A., 1997. Osmotic pressure and viscoelastic shear moduli of concentrated emulsions. Physical Review E, 56, 3, 3150-3166.

Mason, T.G., 1999. New fundamental concepts in emulsion rheology. Current Opinion in Colloid \& Interface Science, 4, 231-238

Mason, T.G., Weitz, D.A., 1995. Linear viscoelasticity of colloidal hard sphere suspensions near the glass transition. Physical Review Letters 75 (14), pp. 2770-2773

Mikkelsen, L.H., Keiding, K., 2002. Physico-chemical characteristics of full scale sewage sludges with implications to dewatering. Water Research, 36, 2451-2462.

Monteiro, P.S., 1997. The influence of the anaerobic digestion process on the sewage sludges rheological behaviour. Wat. Sci. Tech., 36 (11): 61-67

Námer J. and Ganczarczyk J.J., 1993. Settling Properties of Digested Sludge Particle Aggregates, Water Research, 27, p. 1285-1294 
Novak, J.T., Sadler, M.E., Murthy, S.N., 2003. Mechanisms of floc destruction during anaerobic and aerobic digestion and the effect on conditioning and dewatering of biosolids. Water Research, 37, 13, 3136-3144.

Park, C., Muller, C.D., Abu-Orf, M.M., and Novak, J.T. (2006) The effect of wastewater cations on activated sludge characteristics: effects of aluminum and iron in floc. Water Environment Research. 78, 31-40

Sanin, F.D., Vesilind, P.A., 1996. Synthetic sludge: A physical/chemical model in understanding bioflocculation. Water Environment Research, Volume 68, Issue 5, Pages 927-933

Slatter P., 1997. The rheological characterisation of sludges. Wat. Sci. Tech. 36(11), 9-18.

Slatter P. 2001.Sludge pipeline design, J. Wat. Sci. Tech. 44(10):115-120.

Slatter P. 2003. Pipeline transport of thickened sludges. Water 21: 56-57.

Slatter P. 2004. The hydraulic transportation of thickened sludges, Water SA, 30 (5): 66-68.

Slatter P. 2008. Pipe flow of highly concentrated sludge. J. Environ. Sci. Health., Part A, 43:15161520

Spinosa, L., Lotito, V., 2003. A simple method for evaluating sludge yield stress. Advances in Environmental Research Volume 7, 3, 655-659

Sutherland, I.W., 2001. Exopolysaccharides in biofilms, flocs and related structures. Water Science and Technology, 43, 6, 77-86.

Tabuteau, H., Coussot, P., Baudez, J.C., 2006. A new approach to the thixotropic behaviour of sewage sludge. Journal of Residuals Sciences and Technology, 3, 4, 233-240.

Thurston, G.B., 2001. Shear rate dependence of the viscoelasticity of polymer solutions: theoretical model. Journal of non-Newtonian Fluid Mechanics, 9, 1-2, 57-68.

Turovskiy, I.S., Mathai, P.K., 2006. Wastewater sludge processing. John Wiley and Sons.

Wingender, J., Neu, T.R., Flemming, H.C., 1999. Microbial extracellulafr polymeric substances. Springer, Berlin.

Wyss, H. M., Tervoort, E., Gauckler, L. J., 2005. Mechanics and Microstructures of Concentrated Colloidal Gels. Journal of the American Ceramic Society 88 (9) 2337 


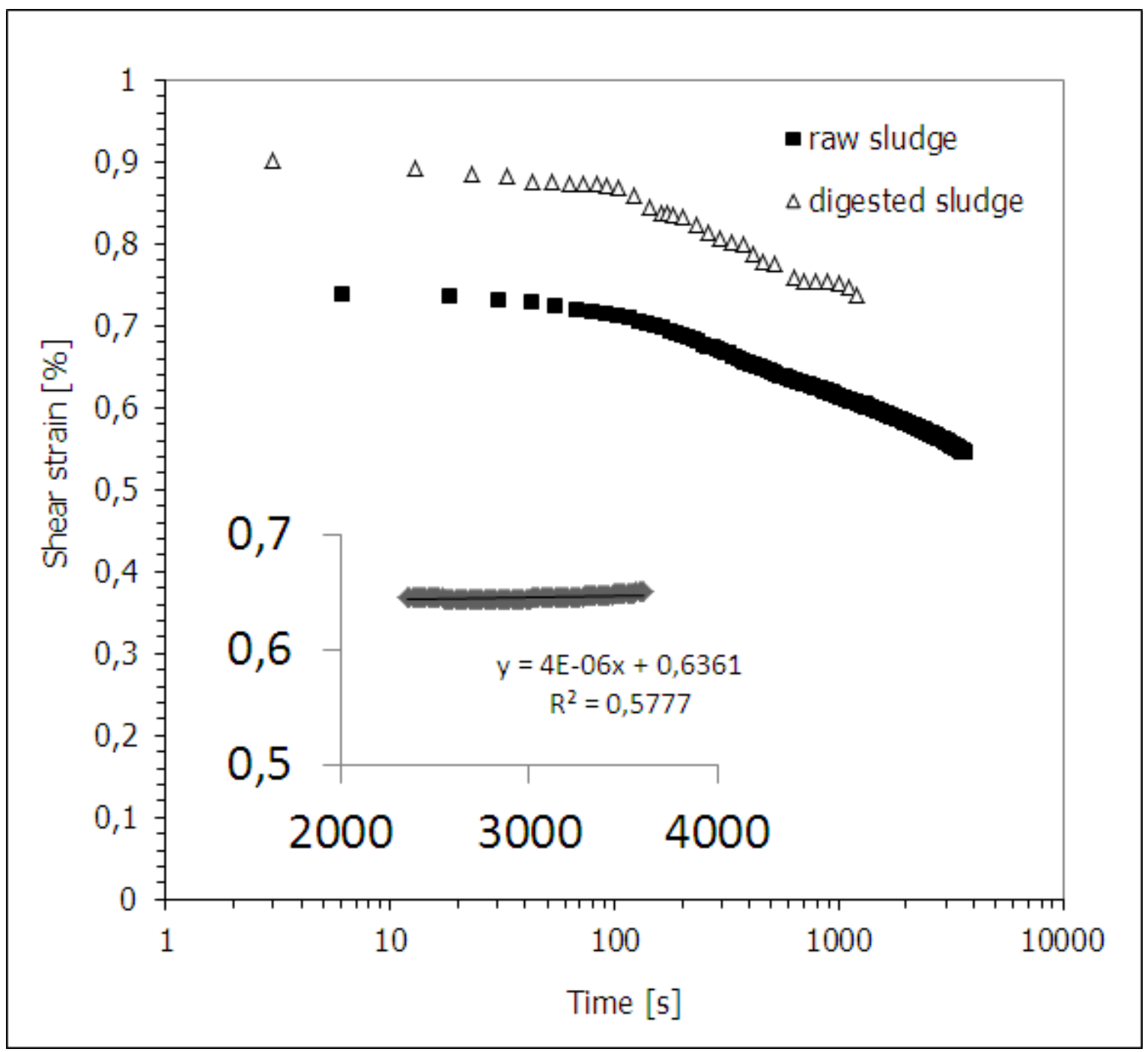

Figure 1: Time evolution of the shear strain in the linear viscoelastic regime for both digested (at 42 g. $\mathrm{L}^{-1}$ ) and raw sludge (at $45 \mathrm{~g} \cdot \mathrm{L}^{-1}$ ) when a constant shear stress is applied, respectively equal to $1 \mathrm{~Pa}$ and $0.65 \mathrm{~Pa}$. The insert shows the strain evolution of digested sludge over longer time at a smaller shear stress $(0.3 \mathrm{~Pa})$ and evidences that shear strain is remaining constant. 


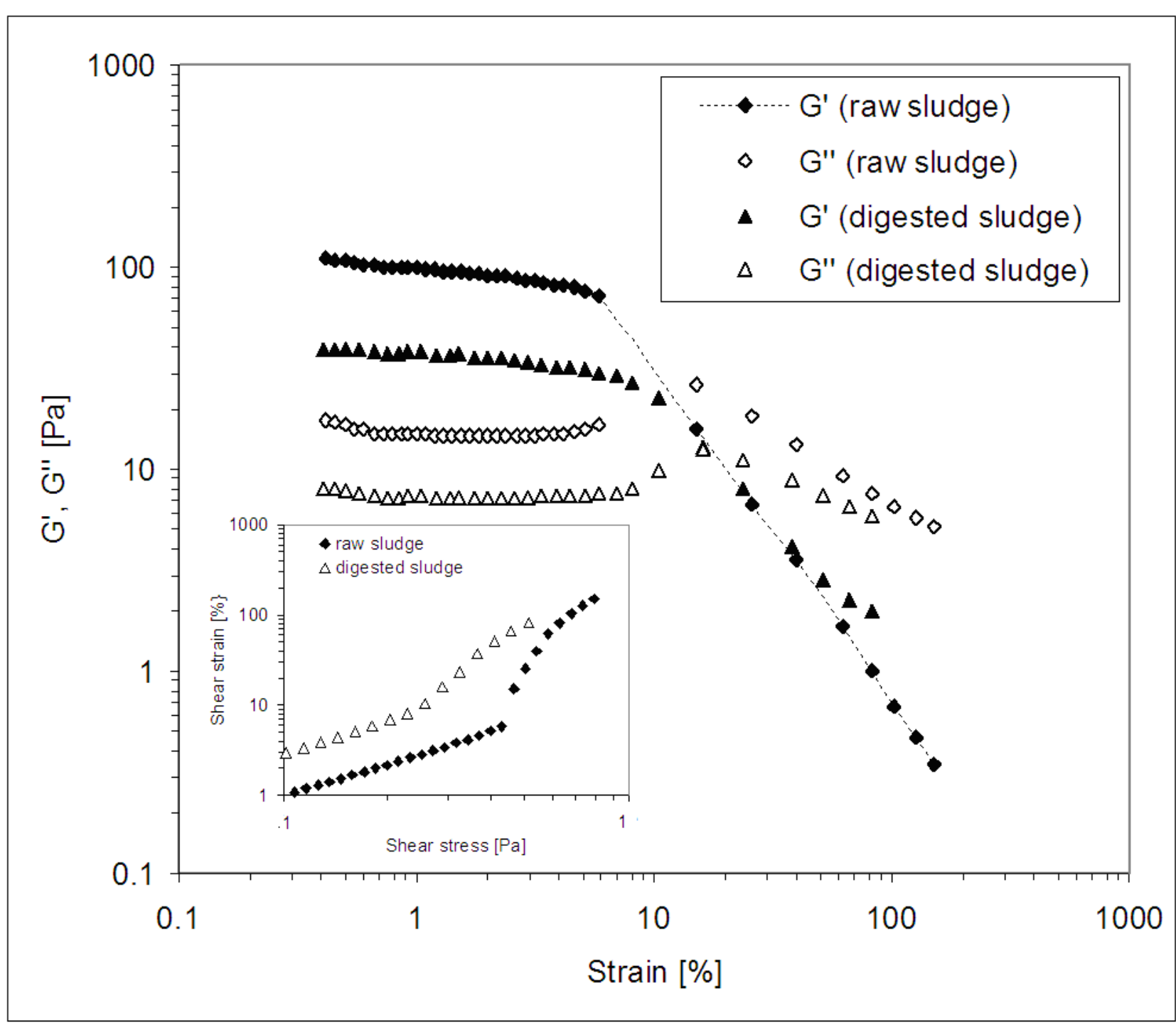

Figure 2: Evolution of storage and loss moduli during stress sweep. The insert shows the stressstrain relationship and the abrupt yielding of raw sludge compared to anaerobic sludge. 


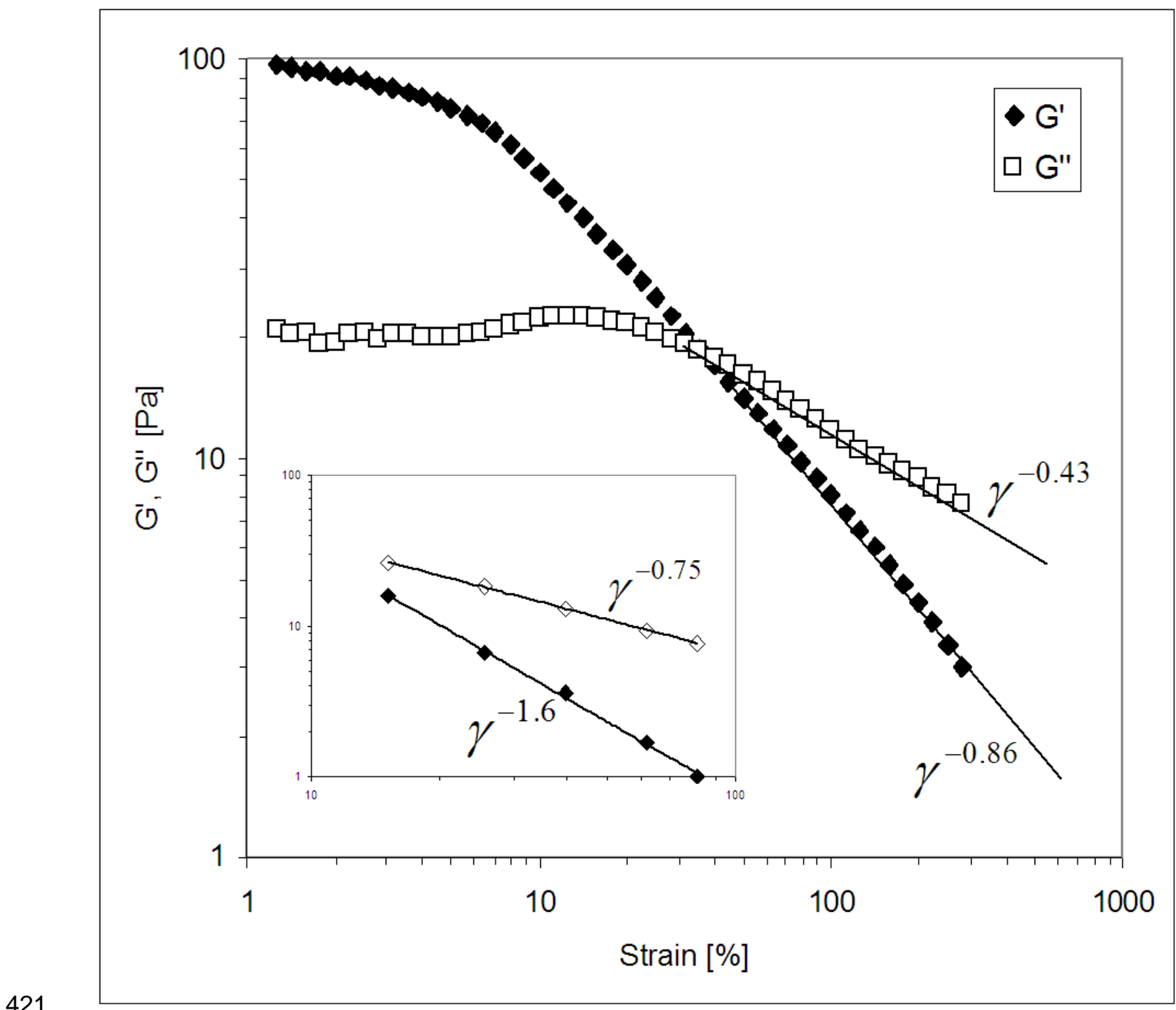

Figure 3: strain dependence of elastic (G') and loss (G") moduli, at $25^{\circ} \mathrm{C}$ and $1 \mathrm{~Hz}$, for the digested sludge concentration of $3.2 \%$. The insert represents the strain dependence of $G$ ' and $G$ " for the raw sludge in the liquid-like regime. 


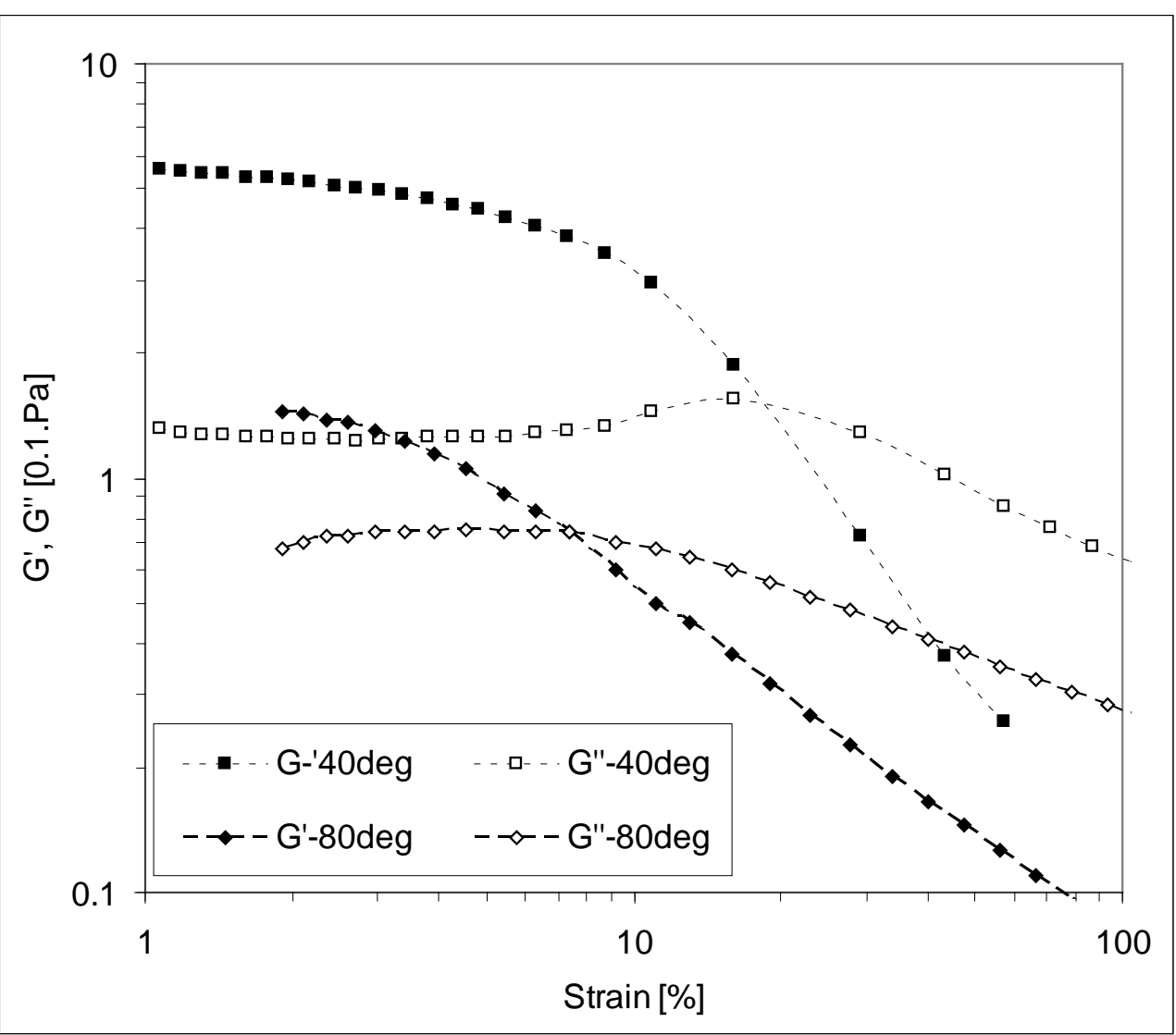

Figure 4: Strain sweep, at $0.2 \mathrm{~Hz}$, for a digested sludge concentration of $3.2 \%$ 


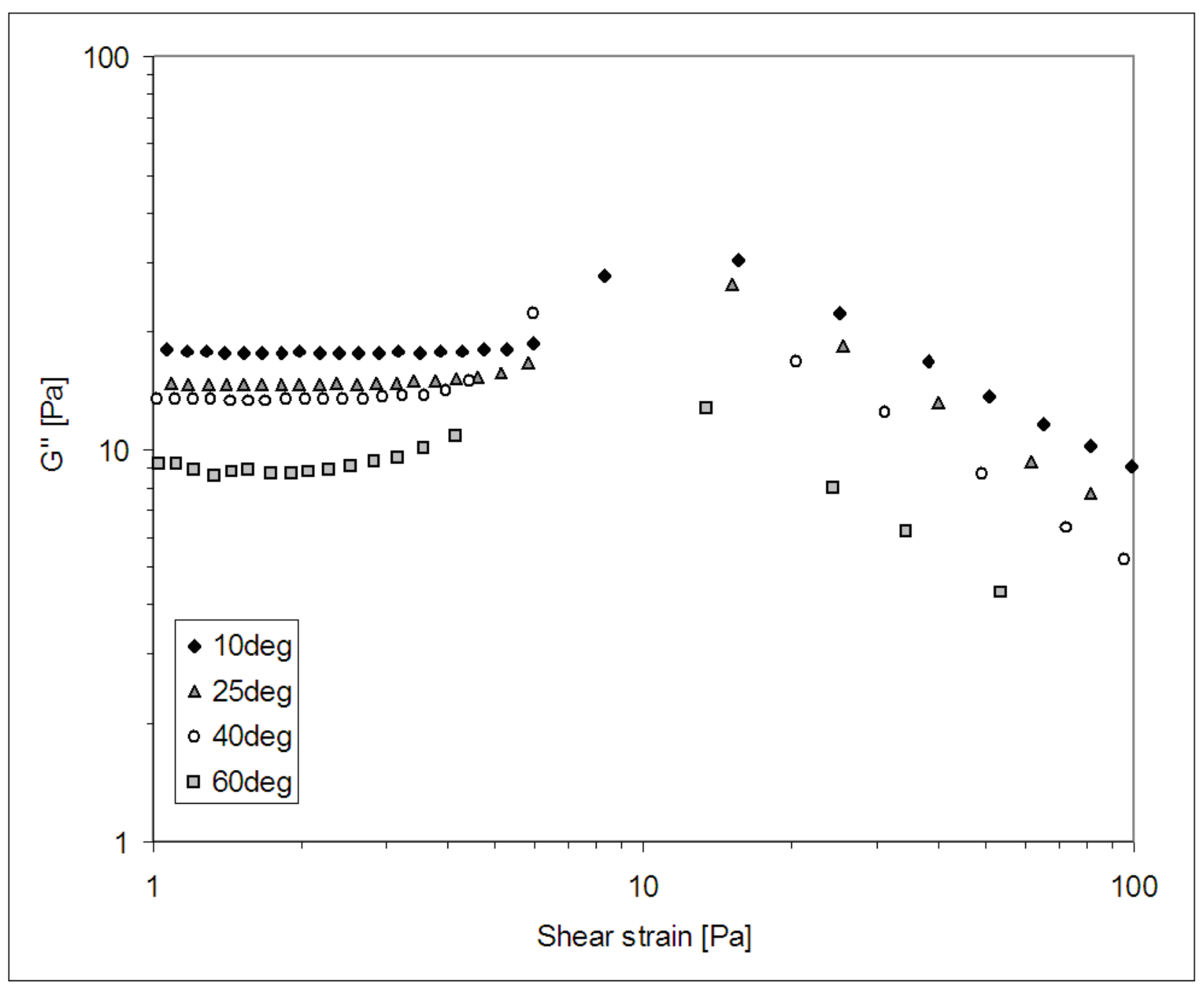

Figure 5: Evolution of G" at different temperatures during a stress sweep for the raw sludge. 


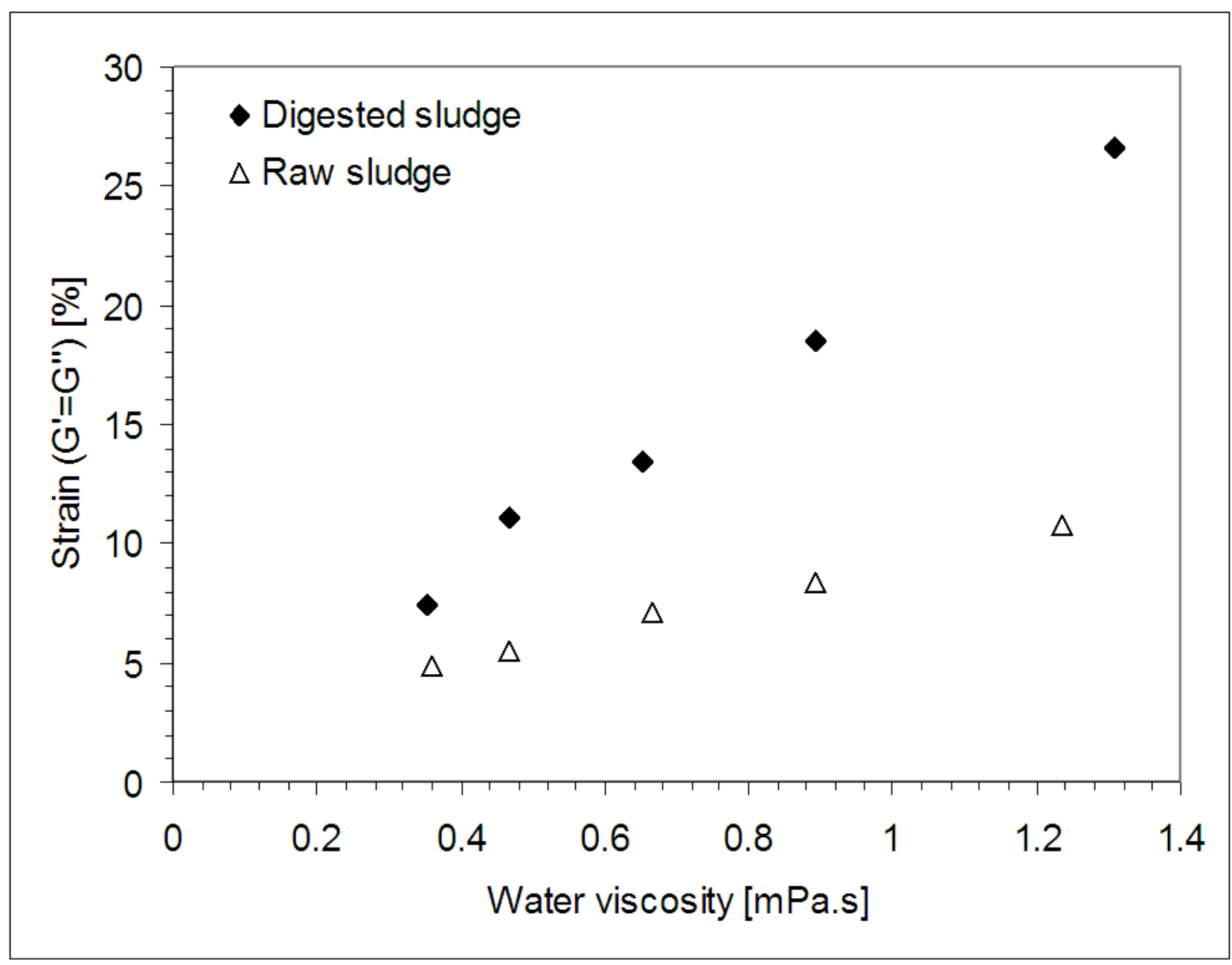

Figure 6: Water viscosity and strain for which $\mathrm{G}^{\prime}=\mathrm{G}^{\prime \prime}$ at $0.2 \mathrm{~Hz}$ for the digested sludge (at $3.2 \%$ ) and $0.5 \mathrm{~Hz}$ for the raw sludge at the 5 temperatures considered $\left(10,25,40,60^{\circ} \mathrm{C}\right)$. 


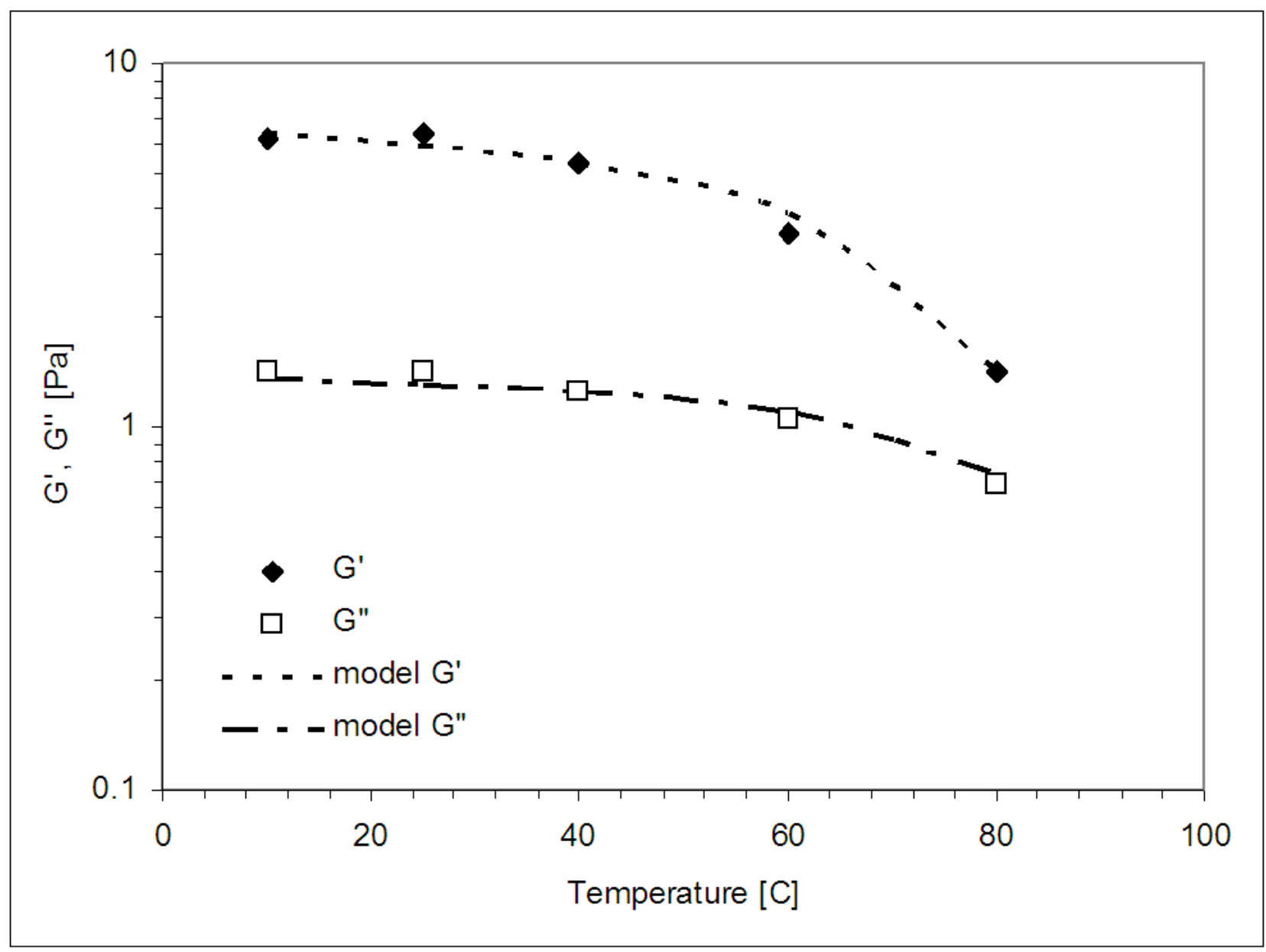

Figure 7: G' and G" both follow a non-Arrhenius law. Model parameters for the 3.2\% sludge $A=12.94 \mathrm{~Pa}, \mathrm{Ea} / \mathrm{R}=50.43^{\circ} \mathrm{C}$ and $\mathrm{T}_{0}=98.40^{\circ} \mathrm{C}$ for $\mathrm{G}, \mathrm{A}=1.61 \mathrm{~Pa}, \mathrm{Ea} / \mathrm{R}=13.77^{\circ} \mathrm{C}$ and $\mathrm{T}_{0}=97.91^{\circ} \mathrm{C}$ for $\mathrm{G}^{\prime \prime}$. 


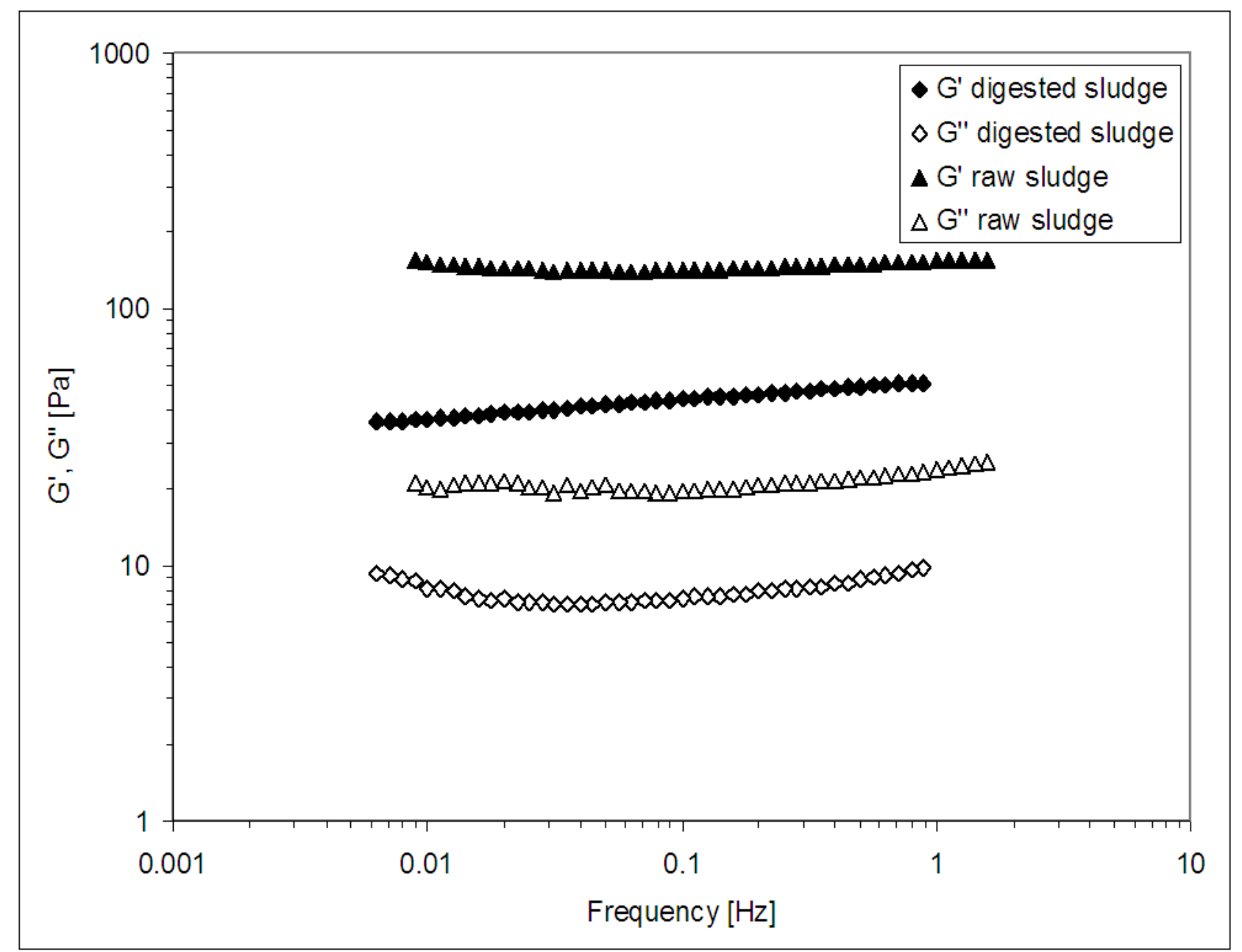

451

452

453

454

455

456

457
Figure 8: Frequency sweep in the LVE regime for both sludges. The slight increase of G' and G" for the raw sludge may be attributed to ageing process 


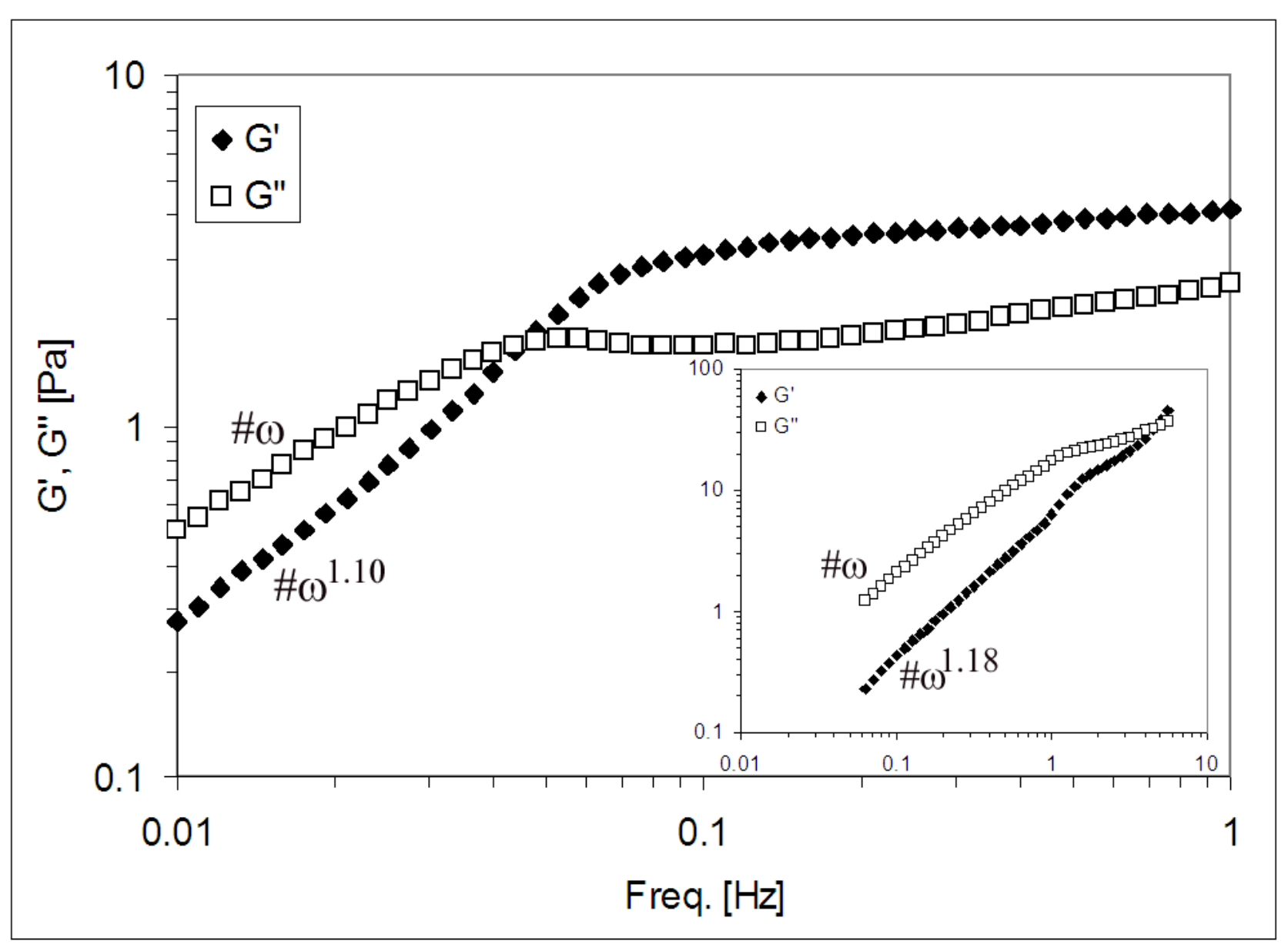

Figure 9: Frequency-dependence of $\mathrm{G}^{\prime}$ and $\mathrm{G}^{\prime \prime}$ at $25^{\circ} \mathrm{C}$ for the digested sludge in the non-linear regime. The insert shows the frequency dependence of raw sludge also in the non-linear regime.

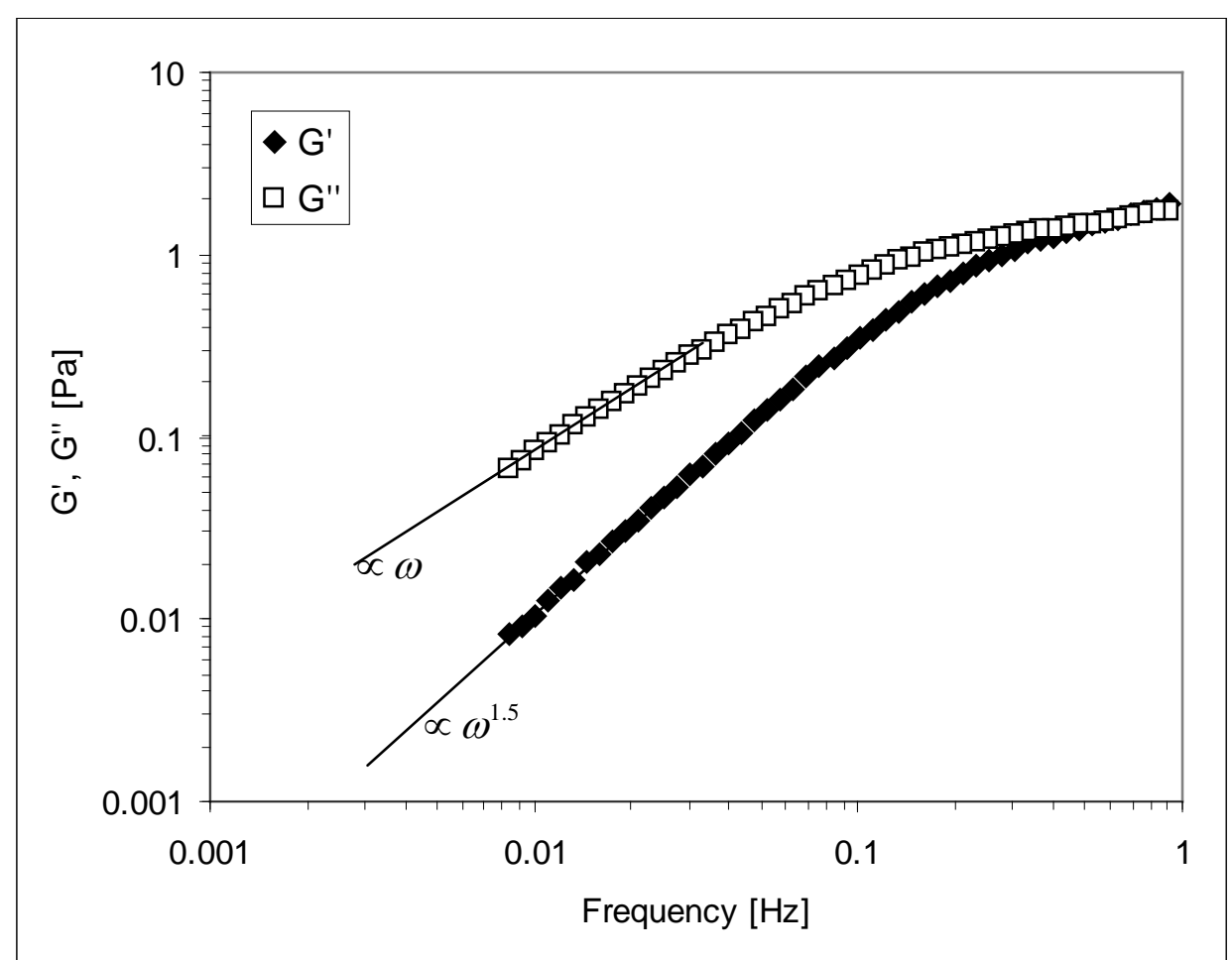

Figure 10: Frequency-dependence of the digested sludge at $40^{\circ} \mathrm{C}$ 


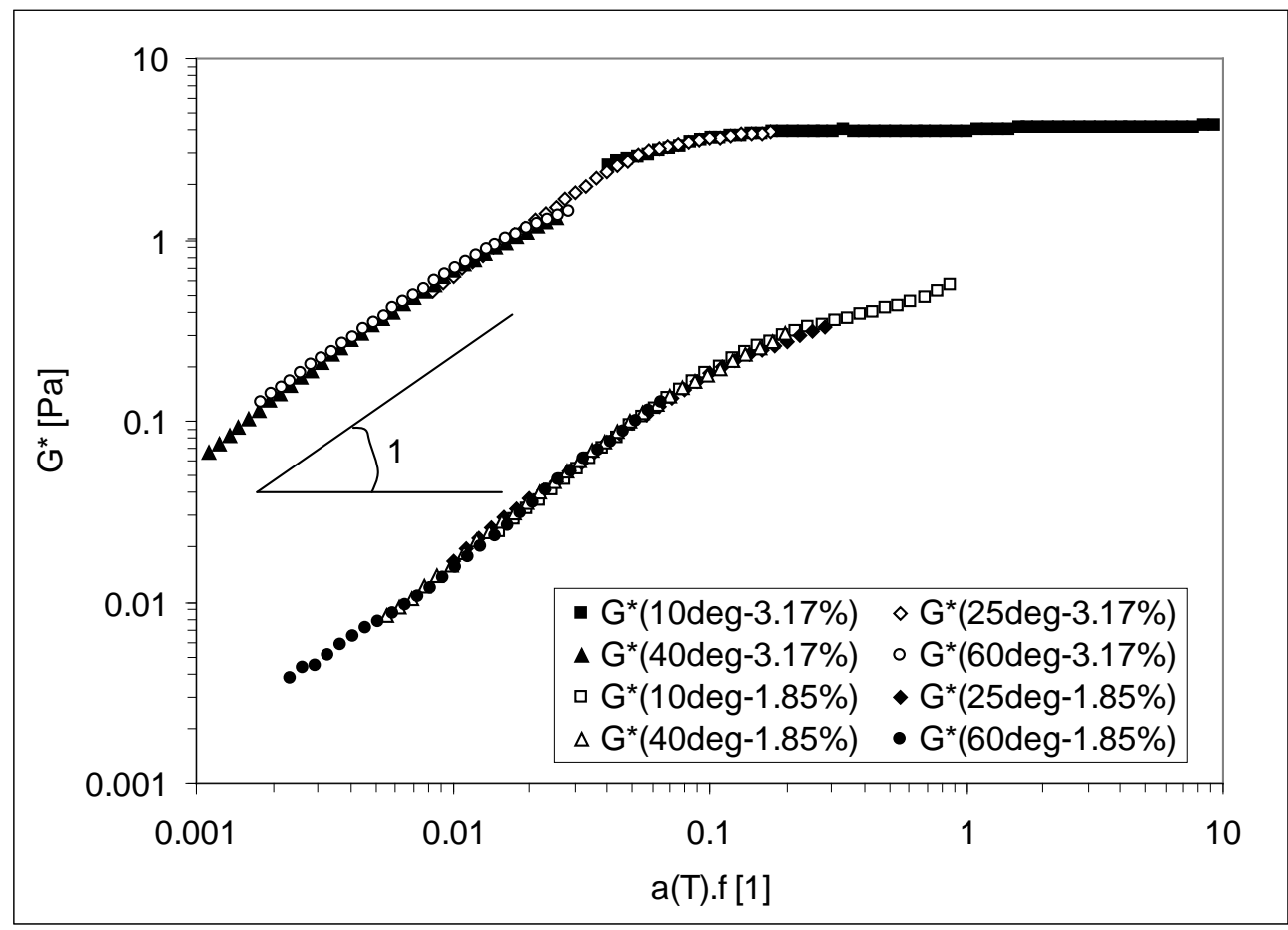

Figure 11: Time-temperature superposition of the complex modulus for both concentrations of sludge.

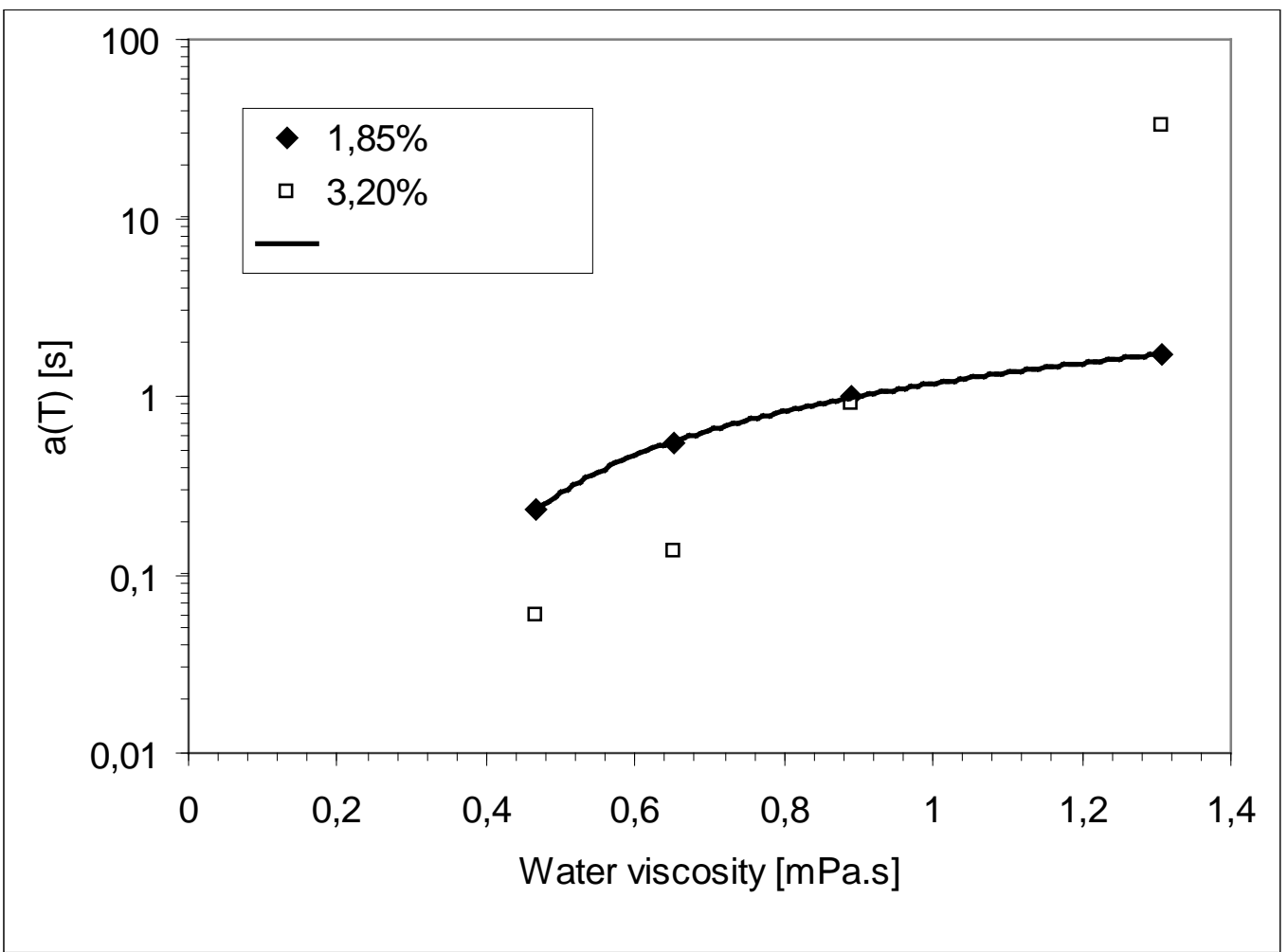

Figure 12: Horizontal shift factor against water viscosity for the $1.85 \%$ and $3.2 \%$ sludge. The solid line represents a linear model. 